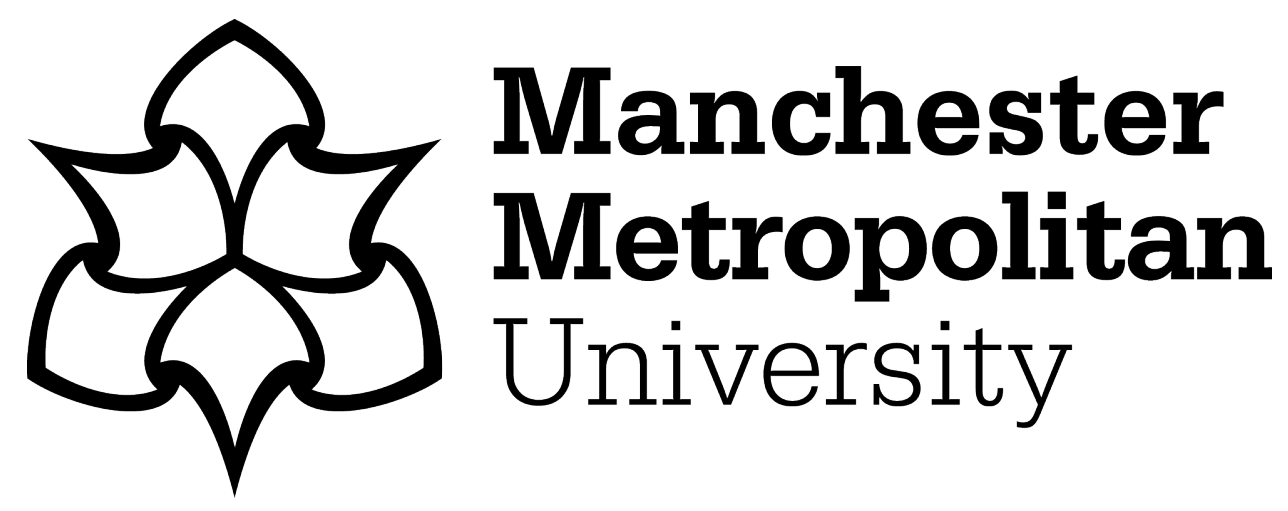

Ormrod, Joan ORCID logoORCID: https://orcid.org/0000-0002-3531-8938 (2018) 1960s surfsploitation films: Sex, the bikini and the active female body. Film, Fashion \& Consumption, 7 (2). pp. 147-163. ISSN 2044-2823

Downloaded from: https://e-space.mmu.ac.uk/624723/

Version: Accepted Version

Publisher: Intellect

DOI: https://doi.org/10.1386/ffc.7.2.147_1

Please cite the published version 


\section{0s surfsploitation films: Sex, the bikini and the active female body}

\section{ABSTRACT}

From 1959 to 1966, approximately 66 Hollywood films were produced to exploit the surfing craze. Surfsploitation, the surf craze of the early 1960s, crossed music, comics, television, advertising and films. Films, especially, focused on the importance of the bikini in their promotion. The bikini, a liminal piece of clothing, conceals and yet reveals the naked body. The film's producers emphasized the appeal of the bikini in the films' cross-media promotion, which promised sex but delivered inane plots, dependent on comedy, pop music and fantasy for their continuing appeal. In the early 1960s the bikini was perceived as an erotic item of clothing from Europe. To appeal to American perceptions of the garment, in fashion and consumerism it was repackaged as related to sport and fun for the female teenage body. Comparing promotional and advertising materials of consumer culture with that of the films, this article explores how the bikini articulated notions of the active yet passive female body in this era on the cusp between the reactionary 1950s and the emergence of second-wave feminism of the late 1960s. Although the promotion from the films promised sex, they were highly moral. Yet the representations of the active female body in the films and their promotional materials reveal the debates around female agency for the early 1960s, an era when girls had to negotiate the societal demands of the reactionary 1950 s with the demands placed upon women by second-wave feminism of the later 1960s.

\section{KEYWORDS}

bikini

teen fashion surfing films gender $1960 \mathrm{~s}$ promotional culture female agency 
1. Although the findings and his methodology were criticized, Kinsey's report was of concern and had great impact on the perceptions of female sexuality in the early 1960 s
From 1959 to 1966, more than 66 Hollywood films were produced to exploit the lucrative teenage market through the surfing craze. Surfing was popularized in California from the early twentieth century with the development of cheaper and lighter surfboards and the subsequent Californian hot-dogging style, a surf technique that emphasized doing tricks on the surfboard. Along with the development of surfing, as an activity associated with California, came a cross media promotion of surfing through pop music, fashion and films, together dubbed 'surfsploitation'. Surfsploitation describes how the 'cool' of surfing was appropriated by the mainstream. Surfsploitation films promotion incorporated sexual exploits, pop music, surfing hijinks, hedonism and youthfulness, the latter three based on their location in California. This article explores how surfsploitation films repackaged bikinis for the active teenage girl body, a body that emerged from the promotional and narrative content of the films.

The bikini began as a marker of sexual license in the early 1960s, but, by the end of the 1960s, it became an indispensable item of beachwear for the fashionable teen, thanks to its promotion in surfsploitation and its related genres of spy, horror and rock ' $n$ ' roll narratives. In this article I argue that surfsploitation was central to the promotion of the bikini as teen wear because of its alignment with surfing, pop music and its Californian setting. Film promotion was overt in proposing the bikini's sexiness and the teen girl's active body. The early 1960s was an era emerging from the reactionary 1950s in which gender roles were rigidly prescribed, and the analysis of gender roles and behaviour enables a reflection on the changing concerns on the potential dangers of the active female body.

Catherine Driscoll suggests that teen movies continuously debate and represent sex (2011: 71) and this can be seen in the promotional materials for surfsploitation films. In the early 1960s, the female body was a central element in debates about sex and sexuality. In the 1950s and earlier, teenage girls were encouraged to act as the guardians of morality in teenage sexual behaviour, saying no to the demands for sex by their boyfriends. Yet, The Kinsey Report of 1953 on female sexuality showed that, by 18 years of age, 68 per cent of girls had experienced premarital sex (Kinsey et al. 1953). ${ }^{1}$ Several factors posed potential problems for the dangers of unrestrained sexual license: the contraceptive pill, although not widely available from 1960 to teenage girls, was an ominous portent for future 'immoral' behaviour. However, sexual liberation for women, through the pill, was slower to translate into societal acceptance of sex outside of marriage. Female roles and aspirations were located in the home as housewives and mothers. In 1963, Betty Friedan critiqued this assumption in her feminist critique of patriarchy, The Feminine Mystique (Friedan 1963). Despite education many women, Friedan noted, became housewives. Domesticity, she argued, was like a prison that curtailed female ambitions.

The perceptions of women's place in domesticity and the drive to marry and raise a family prevailed in surfsploitation films that borrowed many of the narrative tropes of parallel genres of romance, comedy and melodramas. The girls in the surfsploitation films were defined through the virgin/whore binary (Ormrod 2003). Good girls were virgins and they were expected to control the unbridled sexual urges of the boys so that they could settle down into marriage. A host of sexy and sexually available women appearing in European films at the end of the 1950s and into the 1960s, such as Brigitte Bardot, heralded the start of an era when sexual freedom and female
1.

2.

3.

4.

5.

6.

7.

8.

9.

10.

11.

12.

13.

14.

15.

16.

17.

18.

19.

20.

21.

22.

23.

24.

25.

26.

27.

28.

29.

30.

31.

32.

33.

34.

35.

36.

37.

38.

39.

40.

41.

42.

43.

44.

45.

46.

47.

48.

49.

50.

51.

52. 
1. sexuality were becoming ever more prevalent. The bikini represented these new attitudes.

Mass media rhetoric on female sexuality in this era focused on whether a girl should or should not commit to pre-marital sex, as posed in the song, 'Will You Still Love Me Tomorrow' by the Shirelles (1960), in which sex is regarded as fun for teenage boys but could have dire consequences for girls, for instance in unwed pregnancy. Sex comedies starring Doris Day and Rock Hudson, Sandra Dee and Bobby Darin were popular in the late 1950s into the early 1960s but, although they featured comedy, sex was noticeably absent (Haskell 1974). The teen drama film, Where the Boys Are (Levin, 1960), about a party of girls who visit to Fort Lauderdale for the spring break, showed all too clearly the punishment awaiting girls who were too free with their sexual favours. Although the leader of the group Merritt, an intellectual, argued that sex should be freely given without the need for marriage, when faced with the prospect, she declined. Her naïve friend, Melanie, who believed Merritt's liberal ideas and was free with her sexual favours, was the victim of daterape. The film appeared at the cusp between 1950s notions of essentialist gender behaviour and the double standard, where girls were meant to be pure whereas boys were meant to sow their wild oats before settling down to marry a virgin.

Surfsploitation films and culture promoted California as the home of American surfing in the early 1960s. California's allure was confirmed in a survey by Look magazine in 1960, which revealed that 11 per cent of Americans would choose to live there (May 2002). In the post War era, California was perceived as a youthful state, its youthfulness tempered with consumerism and hedonism (May 1988; May 1999). An issue of Cosmopolitan in 1957 described California as a'teenage paradise': [...] [where] 'mountains, beaches and play-conscious cities add up to a teen-age pleasureland' (May 1999: 34). The bikini contributed to the Californian hedonistic and beach-conscious culture as it became associated with freedom, fun and sexiness. Indeed, by the early to mid-1960s, the bikini was regarded as the ideal fashion clothing for the Californian beach and gained acceptance quicker in this region than elsewhere in America from the early 1960s. However, the bikini's acceptance was not guaranteed for there was initial caution over its adoption in America in the late 1950s because of its sexy image and its association with perceived European immorality.

The bikini was a product of the increasing sexualization and eroticization of bodies after Second World War and the desire to shock (Schmidt 2012). The bikini was named after the Bikini Atoll, site of numerous nuclear tests in the 1940s. It was created in 1946, simultaneously by two fashion designers: Louis Réard and Jacques Heim. Jacques Heim called his creation the Atome and Réard called his the bikini. Both were associated with the nuclear bomb but Réard's title became the popular description for the two-piece bathing suit. Such was its scandalous reputation that none of Réard's models would wear it. Instead, he chose a strip dancer, Micheline Bernardini from the Casino de Paris, as his model. Images of Bernadini in this first bikini appear today as daring as any apparel on the beach for it not only sports the very smallest of bras but it is also a thong that reveals her bare buttocks. Its size was also a factor in its designation as a bikini for Réard proposed that the garment could not be described as a bikini unless it could be placed in a small container or drawn through a ring. Unsurprisingly, the Vatican wasted no time in describing the bikini as a sinful garment. 
In Europe the eroticism of the bikini was popularized by stars such as Diana Dors in a fur bikini at the 1955 Venice Film Festival, Ursula Andress as Honeychile Ryder in Dr. No (Young, 1962) and especially Brigitte Bardot at the Cannes Film Festival (1953) to publicize her film Manina the Girl in the Bikini (1953). The latter film was released in America 1958 to cash in on the success of And God Created Woman (Vadim, 1957) on its release in America. In this film, the bikini revealed the natural shape of the female body (Kennedy 2007).

Initially the bikini struggled for mainstream approval in America. The National Legion of Decency crusaded to ensure that the bikini would not be worn in American films. In 1950 Fred Cole, the designer for Cole of California, proclaimed, 'I have little but scorn for France's famed bikinis'. Nevertheless, by 1960 the teenage appeal of the bikini was exploited in pop music in a number one 1960 novelty record, 'Itsy Bitsy Teenie Weenie Yellow Polkadot Bikini', by Brian Hyland that increased its growing popularity. The record hit the top ten in several countries and poked fun at the teenage girl who wore a bikini on the beach but was too modest to let anyone see her wear it. Films and film star interest in the bikini also inspired the trickle-down effect of the bikini from fashion to mainstream: for instance, Ginger Rogers and Marilyn Monroe wore bikinis in advertisements for Catalina swimwear. Despite Fred Cole's condemnation of the garment, by the early 1960s, it gained acceptance, when its erotic image was tamed through music and film. Cole of California introduced a bikini line of swimwear and bikinis were used as promotional attractions in Hollywood films.

To illustrate how the bikini became an accepted item of teen wear, I compare fashion and consumer goods advertising targeted at teenagers featuring bikinis and two-piece swimwear with the promotion of surfsploitation films. To determine the differences and the potential impact on American culture of the bikini in the early 1960s, I analysed twelve fashion and sun tan lotion advertisements targeted at teenage girls that featured bikinis prominently in their imagery. I compared these with 26 surfsploitation films posters to determine the significance of the bikini in the ways in which the female body was constructed. I argue that the films promotion influenced perceptions of the bikini and the active female teenage body as primitive, sexy and wild. The fashion industry promoted the bikini to the teen market through discourses of health, modernity and sexuality, whereas the film posters promoted sexuality through subtext and association.

\section{THE BIKINI, THE BODY AND THE ANOMALOUS AS A CATEGORY}

The bikini is not functional as clothing for it does not offer protection for the body against cold weather. Here, it is worth considering Jennifer Craik's suggestion of the close symbolic relationship between clothing and the body beneath.

Clothing does a great deal more than simply clad a body for warmth, modesty or comfort. Codes of dress are technical devices which articulate the relationship between a particular body and its lived milieu, the space occupied by bodies and constituted by bodily actions. In other words, clothes construct a personal habitus. 
As Craik suggests, clothing is constructed as much by its lived context as the body that it covers. The bikini, worn predominantly on the beach, is constructed by the analogous nature of the beach as a site of potential transgression. It is worn by teenage girls, who are also in an anomalous state between childhood and adulthood. It is also worn on holiday, a temporal anomalous state aligned with leisure, a space and time that allows and prohibits different behaviours from work time (Fiske 1983).

Many of the conflicting elements in the cultural perception of the bikini resulted from the spatial, temporal and cultural discourses that constructed it as an anomalous category. The anomalous nature of the beach, surfing and the holiday were flagged up in John Fiske's semiotic study of beach culture in Australia (Fiske 1983; Corman and Jerome 1998; Trubo and Arkoff 1992). Fiske proposed the anomalous as a category 'that is neither one nor the other but has characteristics of both. This means that it has simply too much meaning, an excess of meaning potential, that derives from its status as anomalous' (1983: 121). Many elements of the films can be regarded as anomalous. The beach is a site in which the boundaries between work and play, clothing and nudity, culture and nature are transgressed. Fiske himself notes the physical anomalies of the beach; it is neither land nor sea and it is a place where culture and nature clash. The anomalous nature of the beach enables the transgression of binaries such as nature/culture, permissible/prohibited and civilization/uncivilized and therefore, the beach is a place that generates a surfeit of meaning.

The bikini also straddles boundaries for it exposes whilst concealing the body. It connotes health but also eroticism and freedom yet constraint. These are connected for, as noted above, in the early 1960s the androgynous female figure became fashionable. This was a body that was young, active and thin. It was a body made to exhibit a mini skirt and the bikini. However, where the bikini connoted freedom and the healthy active female body, it conversely promoted constraint. The body must be constrained from eating too much so that it would look good in a bikini. Thus, the rigid structured of 1950s fashion gave way to what Mary Quant described as clothes for the ordinary girl. However, the corset of the 1950s was replaced by the invisible corset of selfdiscipline and weight control of the 1960s; 'women were freed and enslaved simultaneously' (Schmidt 2012: 90).

The bikini's erotic power was reinforced with the dangers that it posed for it enabled the exposure of the navel in the United States. The exposure of the navel did not seem to be a problem in Europe. In 1953 at the Cannes Film Festival Bardot, aged eighteen, posed on the beach, wearing a bikini that exposed her navel. This was a shocking act for, according to Elizabeth Bronfen, the navel 'echoes the vagina as well as the anus, transforming the stomach into an erotically exciting but also cultural taboo zone' (1998: 3). Bronfen argues that the navel simulated an erogenous orifice and was often perceived as the natural site for sexual intercourse or, by small children, as the place out of which babies were born. The navel, therefore, was regarded as taboo and especially in American cinema. The Hays Production Code forbade 'indecent or undue exposure' and the navel constituted indecent exposure unless it was covered by a jewel. The spectacle of the unconcealed navel was of constant concern in the 1960s and showing the navel did not achieve acceptance until the end of the decade. Even then it was regarded as titillating. For example, in her 1969 fashion collection, Mary Quant clothing revealed 'maximum 
exposure of the navel in a collection heavily emphasizing the widely bared midriff' (Walker 1969: 10).

By the early 1960s ideals of female beauty and body shape changed from the rigid structures of the 1950s with corsets and uplift bras, to a less accentuated female figure. This was a teenage body that was androgynous. Models such as Twiggy epitomized this boyish body and the large-breasted, small-waisted bodies of 1950s fashion and beauty icons became outmoded. Twiggy and Jean Shrimpton were photographed dancing, moving around rather than posing like 1950s models (Steele 1996). Their youth expressed the promotional campaign to hit America in the 1960s from Europe. Youthquake promoted miniskirts and clothing from swinging London, which became a centre of pop culture. The bikini, a garment so minimal, was ideal to display the teenage androgynous body and its alignment with Californian youth culture changed the perceptions of the ideal body shape for, in a bikini, there was no place for an extra ounce of flab (Radner and Luckett 1999).

The promotion of the bikini reflects these potentially conflicting categories as it stresses similar conflicts relating to hedonism, eroticism, health and danger. There is a clear difference in the ways in which the bikini was promoted for the teen girl body in the fashion industry and the film industry centring on sex, Otherness and the active female body. The female body was a site of danger and power. The bikini both exploited this power and revealed but also contained its dangers.

\section{SURFSPLOITATION AND THE RISE OF THE INDEPENDENT HOLLYWOOD STUDIOS}

Surfsploitation films made money in an era when large Hollywood studios were losing money. Film attendances declined by 50 per cent between 1949 and 1959 due to two factors: the destruction of the vertical integration system of film distribution and the growth of television ownership (Caine 2001; Doherty 1988). These factors led to the rise of exploitation film studios who screened their films in independent and drive-in cinemas across America. Hollywood studios were also hit by the growth of television ownership in the late 1950s and, in response, the large studios produced specific cinematic effects such as cinemascope to differentiate the cinematic experience from its more accessible and cheaper rival. The exploitation studios also aimed to differentiate themselves from television with a range of spectacular stunts and lurid promotional tools. They targeted predominantly teenage audiences and, through this, companies such as American International Pictures (AIP) were able to expand their output (Trubo and Arkoff 1992; Corman and Jerome 1998). AIP is the studio most associated with these films and it is usually cited as the exemplar of cross media promotion and sensational methods.

AIP was set up in 1955 by Samuel Z. Arkoff and James H. Nicholson. AIP produced twenty films per year targeting teenage male audiences based on Nicholson's identification of this audience through his Peter Pan formula (Trubo and Arkoff 1992). The Peter Pan formula was based upon the assumption that young teenagers wanted to watch films frequented by older teenagers. Older male audiences did not want to watch films produced for female audiences, and yet their girlfriends would go to see a film produced for older males. Therefore, the ideal audience was the 19-year-old boy. The marketing campaign and selling point became the most important aspect of the film as an AIP marketing brochure claimed:

1. 2. 
[...] we want to know at the very outset exactly why we are marketing a certain motion picture, what we have to sell, what the exhibitor can do with the property in his territory and what inherent exploitable values are available for immediate development.

(McGee 1984: 165-66)

In 1963 AIP produced Beach Party (Asher), the model for later surfsploitaiton films. Using promotional tactics devised in the early 1950s, they focused on key factors of sea, sand, sun, sex and bikinis as the selling points of the films, as admitted by James Nicholson, 'We are fully aware that our beach bunnies in bikinis are a prime attraction for the teenaged boy who brings his teenaged girl friend to the theatre to see the barechested surfers' (McGee 1996: 150). These films suggested the power inherent in the female body and, I argue, the bikini exposed, whilst containing, the threat of the powerful female body.

Surfsploitation films were part of a cross media promotion targeted at teenagers who were identified as potentially lucrative audiences (Doherty 1988). Along with the easier availability of surfboards and media promotion, the mass media were implicit in the explosion of teenage interest in surfing. Pop music dwelt on surfing fun and girls in songs by the Beach Boys and Jan and Dean. Bikinis also featured in several of the Beach Boys lyrics. For instance, in 'California Girls' they describe how, 'I dig a French bikini on Hawaian island dolls/ By a palm tree in the sand' (Beach Boys 1965). The Beach Boys also featured in some of the movie surfsploitation. Brian Wilson and Gary Usher composed the score for Muscle Beach Party (Asher, 1964a) and the Beach Boys sang several songs in The Girls on the Beach (Whitney, 1965). However, one film Gidget (Wendkos, 1959) is credited with instigating the surf boom of the late 1950 s and the early 1960s.

Gidget starred teen star and girl/midget Sandra Dee and was based on the true story of a teenage surfer girl, Francis Lawrence. Such was the popularity of the film that it was followed by sequels and a television series. The bikini did not appear in the film or its promotion. Although Columbia produced several teen-related films, it did not use the sensationalist promotional tactics of the independent film studios. The press packs, posters and trailers for the films emphasize key themes and terms such as pop music, surfing and teen stars used by AIP to attract teenage audiences and, of course, the bikini.

Such was the iconicity of the bikini that it frequently featured as a garment without a female body. Often, the camera dwelt upon the bikini torso, mostly the female bottom, ignoring her face and breasts. This disregard denied the girl her identity beyond the bikini. For instance, the poster for How to Stuff a Wild Bikini (1965b) featured two bikinis that the female body implied in the lettering for the film title and cast list. The film's opening showed the beach party gang encountering a bikini on the beach and one of the surfers proclaims,

'Dig that wild bikini!'

His girlfriend replies,

'It ain't nothing without the stuffing'.

This exchange infers that from the male point of view the bikini has an identity of its own and this differs from the female point of view. The gang then begin to sing about the merits of stuffing the bikini with the female body 
whose ideal measurements are 36/22/36. This measurement of the figure has relevance to the discussion of body shape and mass later in the article.

The rest of the article deals with the ways in which the bikini was exploited in the fashion industry. This is compared with film promotion and narratives to show how and why the bikini became so iconic in Californian and teen culture from the early 1960s through the active body that was an integral part of the promotion and film narratives.

\section{SURFSPLOITATION IN 1960S HOLLYWOOD FILMS AND CULTURE}

Beach Party (1963) was pitched by William Asher, the director, to Samuel Z. Arkoff and James Nicholson, who, at first, wanted to make a transgressive teen film filled with drugs, sex and delinquency. Asher, sensing a change in attitudes towards teenagers and in teen culture, protested, claiming that people were tired of Juvenile Delinquency (JD) films. Instead, he proposed that the film featured teenagers having good, clean fun without the rule of parents or school (Trubo and Arkoff 1992). Beach Party, the first in the series, formed the paradigm for most of the other films.

In Beach Party a group of surfers go on holiday to have fun and surf. However, their fun is interrupted by a group of bikers, led by Eric von Zipper (Harvey Lembeck lampooning Marlon Brando in The Wild One (1953) and Professor Robert Orville Sutwell (Bob Cummings), an anthropologist researching teenage sexual rituals. There are romcom-type misunderstandings between the leaders of the group, Dolores/Dee Dee (Annette Funicello) and Frankie (Frankie Avalon) punctuated by surf sequences, dancing, comedy, singing and ending with a general celebration dance, a slapstick chase, a fight or a kiss between the lovers in the surf. Such was the success of the film that it was quickly followed by six other films starring most of the same cast reprising their roles and recycling many of the same plots.

The Beach films were produced in a very short timescale - no more than three months and so their content reflected the cultural concerns of early 1960s America from the Cold War, the British beat invasion to avant-garde art, homosexuality and juvenile delinquency (Morris 1993; Rutsky 2000; Ormrod 2003). Nevertheless, they seemed rooted in a fantasy never-never land of bland teen culture that appealed because they presented a comforting return to a more stable era before the Vietnam War, the assassination of President Kennedy, fears of nuclear conflagration and the uncertainties of the Cold War (Morris 1993). They allayed cultural concerns whilst promising an encounter with the exotic Other (Morris 1993; Rutsky 2000).

The bikini was a crucial marketing device in the more spectacular stunts promoting the films. For instance, Annette Funicello, accompanied by six bikini-clad beauties, was sent on tour to promote the films around America. To promote one of the films, a Miss Bikini Contest was held at the New Mission Theater and the Geneva Drive-In with fifteen dancers. The prize was an expenses paid trip to Hollywood and a part in a beach party film with a payment of $\$ 100$ for the appearance. Annette also promoted her own line of sportswear Patti Chandler hostess for the Clarise Sportswear Brand line 'It's Annette'.

Along with AIP's beach films a host of other companies produced their own versions, often copying the AIP narrative model. There were related films with similar storylines set in ski resorts, horror films and spy-related fantasies. All featured bikinis in line with AIP's promotional model. Films produced

1. 2. 3. 4. 5. 6. 7. 8. 9. 10. 11. 12. 13. 
1. by other companies such as Columbia, Paramount, United Artists and 20th

2. Century Fox are included in the analysis to show the prevalence of the bikini 3. as a promotional tool. For instance, the winter-based films such as Winter A-Go-Go (Benedict, 1965) featured girls skiing in bikinis, describing them as 'snow honeys'. This film features the snow honeys sunbathing on the hotel balcony against a snowy landscape backdrop. Bikini features in the title of Dr. Goldfoot and the Bikini Machine (Taurog, 1965), a spy spoof, and it seems entirely unnecessary except as an exploitative strategy.

I now want to turn to the use of the bikini in advertising for fashion and consumable goods to compare the difference in the representation of the active female body with the films' promotion and narratives.

\section{MARKETING THE BIKINI TO TEEN AMERICA: MODERNITY, HEALTH AND THE CHASTE TEEN BODY}

The bikini was marketed as both fashion and sports item when it was first promoted in America. It was adapted to American tastes with 'built-up cups and modestly cut leglines' (Schmidt 2012: 90). The rise in youth culture had much to do with the change in the bikini's popular acceptance as in the postWar period teenagers were creating their own fashions, music and subcultures. Despite the reservations of Cole of California in the early 1950s, the company developed their own line of two pieces and bikinis and, as Granat Kirse May states, they 'domesticated the bikini, making it safe for young beachcombers and appropriate for California Girls' (May 2002: 118). An article published in Seventeen \#20, September 1961, 'Pinky pastels are flourishing in Los Angeles', claimed that the bikini was worn in California more than any other part of America and, as a state with a lucrative teenage market, bikinis were designed and promoted for the teenage figure (May 1999: 127).

Three themes emerged from the analysis of the advertisements: modernity/ functionality; nature/health; and sexiness/magic. Many of the advertisements featured pastel colours, mostly an innocent pale pink. Annette Funicello's swimsuit in the Tanfastic advert is pale pink stripes. An advert from 1966 published in Seventeen magazine for Escape Swimsuits also features a girl in a pink bikini kneeling on straw in a barn setting, behind her a pink egg broken in two; the copy reads 'Break out of your shell [...] peek-a-boo bikini [...] chic enough for any chick'. This copy infers that the bikini is the means to introduce the teenager into maturity and sexuality. A similar alignment of the pink bikini with the promise of sexuality is in a Cole of California advertisement with the logline, 'Confessions of a Cole crazy girl', where the model reclines on a sun lounger. The model, who resembles Sophia Loren, is contextualized in what looks like a garden setting on a pink sun lounger. Her bikini covers her navel and is fastened around the waist with a chaste pink bow. Her eyes belie this innocent context as they are half closed, knowing. Her lips are sensual and full. The image is anchored with 'confessions' in the logline that holds the sexual frisson as it reflects titillating spicy confession pulp novels and magazines.

Modernity and functionality were connoted in manmade fabrics used to make the bikini more comfortable and keep its shape. Early versions of the bikini were not functional as a sports item as they were made of cotton or jersey and tended to bag in the water, possibly one of the reasons why the girl in the itsy-bitsy-teenie-weenie was afraid to come out of the water. Changes 52. in fashion, the body and the fibres used in their construction enabled the 
acceptance of the bikini as a fashionable beach garment in the early 1960s (Steele 1996). Early bikinis were boned and cupped to shape the female figure. Man-made fibres, which appeared from the late 1930s, enabled the bikini to allow the natural shape of the female body and aligned it more with outerwear and sportswear than underwear or foundation garments. Advertisements aligned these new fabrics with modernity and functionality. A typical example in an advertisement for a Roxanne bikini outfit in 1965 notes how the fabric stretches and states 'I don't know beans about Vycron Polyester. But I like the way Roxanne mixed ' $n$ matched it [...] with Vycron everything's dry almost before you can say "where's the suntan lotion?"' Similarly, an advertisement for Avril Rayon noted the functionality and comfort of the fabric: 'the fabric is woven with Avril Rayon. So it must stay shapely, resilient, strong, colorful, lustrous. Comfortable and cool, too'.

Nature and health discourses were reflected in the associations of the bikini and two- piece swimming costume with the beach, sports and particularly, surfing. Surfing was shown in the consumable products of the surfing industry: the surfboard, the Woodie (a car that carried surfboards) and blonde surfer boys. The connections with surfing were made in the names given to the bikinis and two pieces, for instance in a Rose Marie Reid Juniors swimsuit advertisement of 1965 in which swimsuits are named after surf terms (cowabunga), Californian surfing breaks (San Onofre, Rincon) and surfer girls (Wahine).

The beach and surfing also connoted health and cleanliness as it was a place where one could become heathier through exercise and exposure to sunlight. It might be assumed that health would be connoted by the active female body; however, few of the adverts depicted the active female body. Most showed girls reclining on the sand or a sun lounger, being carried by men, standing on surfboards rather than surfing. Rather than exercise and the active female body as the signifier of healthy lifestyle, in these advertisements, the sun tan was the signifier of the healthy female body. However, the sun tan insinuated issues of Otherness and racial purity that dated to the beginning of the twentieth century.

In the early twentieth century, the sun tan became a means of demonstrating a healthy body. Sunlight was shown to cure several diseases such as rickets. Fashion leaders such as Coco Chanel in France led the trend towards tanned skin. By the 1940s sun bathing was regarded as beneficial to health and sun lotions were sold to help people develop healthy tans. Examples of tanning and its healthful effects can be found in a piece of cross promotions for Tanfastic dark tanning lotion. Both align sport and the sun tan. For instance, an advertisement for White Stag Sportswear shows a woman reclining on the sand with a bottle of Tanfastic lotion, 'The creamy white lotion that gives you a honey of a tan in a hurry!' The use of 'honey' aligns sex and health for it describes the colour, implies the health-giving attributes of honey but also the sexy surf'honey' on the beach. The second advert, of 1964, cross promotes Tanfastic with AIP's Muscle Beach Party (1964a) as it features the stars Frankie Avalon and Annette Funicello with a group of surfers in the background in a Woodie. The copy states that with Tanfastic 'you'll tan really deep, really dark'. Yet, despite the drive to tan,'really deep, really dark', in these advertisements, everybody is Caucasian. The suntan as a signifier of health and beauty dated to the beginning of the twentieth century and the eugenic movement. Eugenics aimed to improve the genetic pool of humanity; however, it was predicated upon the superiority of certain ethnicities, classes and the inferiority of those

1. 2. 3. 4. 5. 6. 7. 8. 9. 10. 11. 12. 
1. who did not conform to idealized bodies. Unlike France, which embraced 2. Josephine Baker, a woman of colour, into its culture, black bodies were not 3. evidenced on the beach and in this era, most American beaches segregated 4. black and white bodies.

5.

6.

\section{OTHERNESS AND CONTAINING FEMALE POWER IN SURFSPLOITATION FILMS}

Segregation and its connections with Otherness, sexiness and whiteness were evidenced in surf film narratives and their promotion. The promotion and narrative themes emphasized sex, surfing, bikinis and rock ' $n$ ' roll. However, the morality expressed in their stories looked back to the 1950s and, although the promotion promised much, the film's content was often bland, frivolous and moral. Indeed, Samuel Z. Arkoff claimed that they were the most wholesome movies in Hollywood (Trubo and Arkoff 1992). The films addressed gender relationships through their promotion of surfers as all-American boys with healthy masculine urges and all-American girls whose job was to allay fears of a crisis in masculine power whilst maintaining their virginity (Ormrod 2003). However, they also did much to promote the wholesome aspect of the bikini, despite its salacious reputation.

The female protagonist of many of the AIP films Annette Funicello (Dee Dee, Dolores) added to the wholesome aura of the films. Funicello, described as 'the guardian of teen-age morals' by Look, was a Disney Mouseketeer, the girl next door and one of the clean teen stars described by Doherty. Bad girls tended to be foreign such as Eva Six in Beach Party or the Contessa in Muscle Beach Party, and they exuded sexuality. Even when Chris Noel is described as 'Devastation in a bikini', in Beach Ball (Weinrib, 1965), she remains a good girl who waits for a wedding ring before allowing sex (Lisanti 2005: 170).

Promotion started with the title; James Nicholson suggested that '70\% of a picture's appeal to an audience is in the title' (May 1999: 174). Thus the bikini was exploited in many of the titles, for instance, Bikini Beach (Asher, 1964b), How to Stuff a Wild Bikini (Asher, 1965b), The Ghost in the Invisible Bikini (Weis, 1966) and It's a Bikini World (Rothman, 1967). Films from the pop spy genre also exploited the bikini as in Dr. Goldfoot and the Bikini Machine (Taurog, 1965). Of the 23 film posters analysed, all, even those that promoted skiing and spies, featured bikinis on active and healthy female bodies. Unlike the decorated and printed bikinis in fashion adverts, the bikinis in film posters were skimpier and, in many cases, they were made from a white or a plain, rather than printed fabric for greater impact. Although some girls'bodies were prone, in the arms of boys or monsters, most were energetic: they danced, surfed, skied, drove cars, fought, sky-dived, carried weights and played in the surf. The imagery was anchored by the rhetoric of wildness, youth and sexiness. This can be seen in the exhibitor's campaign book of For Those Who Think Young (Martinson, 1964) where girls dance, are carried by surfers on the waves and run through the surf carrying their boards. The copy states, 'They're riding the crest of a wave...in the freshest, youngest, wildest picture of the year!' (Figure 1).

Much of the copy in the posters promised sex through innuendo and the bikini was a major selling point of this promise. The logline for Muscle Beach Party (1964a), the sequel to Beach Party (1963), was 'Surf, sand \& bikinis!' this was expanded with 'When 10,000 biceps go around 5,000 bikinis [...] you 52. know what's gonna happen!'. The press pack for Beach Ball (Weinrib, 1965), 


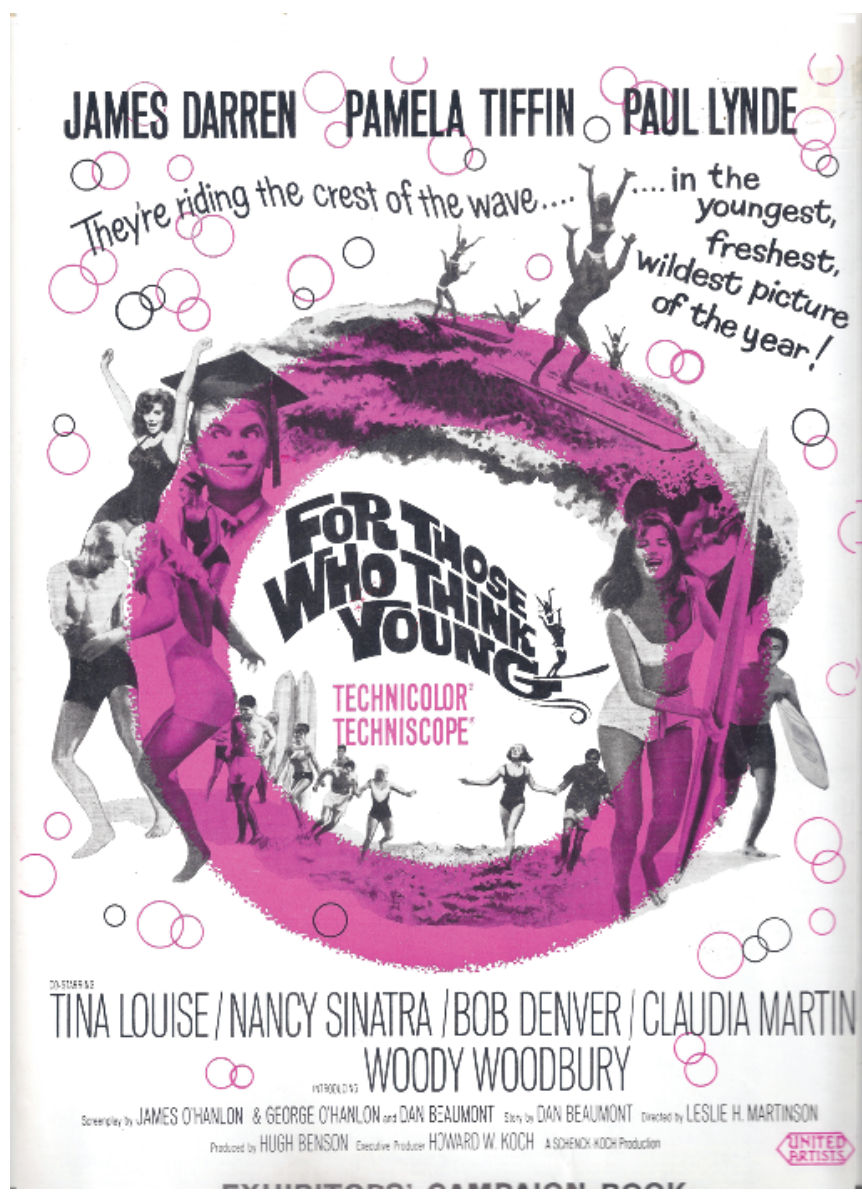

1.

replicating a newspaper cover, proclaimed 'Bouncin' bikini babes and their brawny boyfriends in Beach Brawl'. The promotion for spy comedy Dr. Goldfoot and the Bikini Machine (Taurog, 1965) told how Dr Goldfoot created thirteen female robots to seduce the world's richest men. The film's promotion suggested the malleability of the bikini-clad fembots as 'lush bikini babes were made to perform'. The posters advertising the film depicted a fembot and the copy suggested the joint dangers of sex and death, "This is a bikini machine. It has a kiss button and a kill button. You have to know which button to push!'. That the robots were beautiful women, wearing bikinis, suggested the promise also of sex without strings for, by pushing the right button, they would be bound to obey.

Sex, surfing and music were aligned through discourses of primitivism in the films narratives and promotion (Rutsky 2000). Although by the early 1960s the sexuality and violence of rock ' $n$ ' roll were tamed by the clean teen phenomenon, the films used references to the primitive in the commentary of adults within the narratives and the roots of rock ' $n$ ' roll, surfing and bikinis in 
Beach Party featured Robert Cummings as a professor of anthropology researching the pagan rights of the teenagers on the beach that he likened to 'the Samoan Puberty Dance all over again'. The cast list for The Beach Girls and the Monster (1965) featured the Watusi Dancing Girls from Hollywood's Whiskey a Go-Go Club, Sunset Boulevard. The Watusi dance was popular in the early 1960s and was inspired by the Tutsi tribe dancers in the film, King Solomon's Mines (Bennett and Marton, 1950). It was popular in the surfing subculture of the early 1960s and inspired several pop songs.

Pop music's evocations of sex and the primitive were an attraction to teenage audiences in the early 1960s and, as R. L. Rutsky suggests, 'teens listening to rock-and-roll music and dancing in a way that was already seen by the guardians of morality as heavily sexualized, and doing so in the titillating attire of swim trunks, and, especially, bikinis' (2000: 17). Rutsky (2000) and Robin Canniford (2013) both connect surfing with primitivism. The pop music in the films connoted Otherness because it had roots in the rock ' $n$ ' roll of the 1950s, music that was connected with juvenile delinquency. More worryingly for white middle-class America, rock ' $n$ ' roll presented the incursion of black into white culture through its connections with jazz and rhythm and blues. The bikini and surfing also connoted Otherness as both had their roots in third-world cultures, especially the South Seas. Otherness and the primitive, therefore, often feature in the plots in binaries of magic/objectivity and sex/ asceticism and together they connote the dangers of the unconstrained female body.

In How to Stuff a Wild Bikini (Asher, 1965b), a witch doctor (Buster Keaton) conjures up a magical bikini with a beautiful girl in it to distract the men on the beach. Interestingly, the stories also relate to other magical female characters in sitcoms of the early 1960s as the witchdoctor's daughter is played by Elizabeth Montgomery, who played Samantha, the witch, in Bewitched (1964-70). The bikini is made from leopard skins and connotes the female body as animalistic and catlike. In Beach Blanket Bingo (Asher, 1965a), Lorelei (Marta Kristen), a mermaid, saves Bonehead (Joel McCrea) from drowning. The woman as mermaid has traditionally been regarded as a sign of female erotic power. However, in this film, the mermaid is permitted to use her legs only a few times in their life. When Lorelei wishes to seduce Bonehead she makes a bikini 'out of a parachute I found on the bottom of the ocean'.

As discussed above, the navel was deemed taboo in early 1960s America. Even the surfsploitation films hesitated at showing the exposed navel. Annette Funicello, star of many of the films and under contract to the Disney Corporation, was contractually obliged to conceal her navel (this was done on the posters but not in the films). The navel was often airbrushed out of AIP posters despite their hyperbolic claims of sex. For instance, all female navels are airbrushed out in the poster of The Ghost in the Invisible Bikini (Weiss, 1966), except for that of a girl wearing a monster mask. Nevertheless, the dangers posed by the navel were made all too evident in the copy for $D r$. Goldfoot and the Girl Bombs (Bava, 1966), a spoof spy comedy, starring Vincent Price as the Doctor who constructs lethal fembots as walking bombs, literal bombshells. The trailer states that the robots are 'programmed for love and destruction'. The promotional copy aligned the explosive effects of the bikini with the sexual threat of the navel, 'Meet the Girls with the Thermo-Nuclear Navels'. Indeed, when combined with the bikini's roots in its association with nuclear power, the films showed how the female body contained and was 
contained by the magical and explosive power of the bikini. This was shown in the effects of the bikini-clad female body on men.

The active female body posed dangers in its magical abilities to telekinetically move men through its dancing, hip-swinging action or even just strolling along the beach. The opening of Bikini Beach (Asher, 1964b) features an anonymous female in a bikini whose innocent stroll along the road and onto the beach causes mayhem: a man crashes his car, Deadhead (Joel McCrea) cooking a steak drops it in the sand and yet cannot stop himself from gazing at her departing body. A pair of lovers, about to kiss, are interrupted by the boy's longing gaze and a surfer on a skim board crashes into the sea. In Beach Blanket Bingo (Asher, 1965a), a girl's bikini clad body causes Buster Keaton to fall in the sand.

However, of all the active female bodies causing mayhem, that of Candy Johnson, Miss Perpetual Motion's go-go dancing, is the most powerful. Candy Johnson featured in four of the Beach Party films. She was described in the promotional materials for Muscle Beach Party as 'the phenomenon of the century [...] [a] [...] bundle of endless energy' and that she loses five to fifteen pounds nightly 'when performing in supper clubs'. In many of the films she wears a staid two piece that does not reveal her navel, rather than a bikini. However, this does not stop her gyrating body movements that are emphasized through rows of tassels. In Muscle Beach Party Candy, wearing a be-tasselled two-piece trouser suit, knocks a surfer out of the water with her swivelling hips. Later, dancing on the bar, she knocks a surfer off his seat and the earrings out of Cappy's (Morey Amsterdam) mask. In the final brawl of the film Candy is exhorted to use her'secret weapon' to stop the fight, which she does. However, even she is unable to completely contain her body's power for, at times, she accidently hits the wrong target.

Despite the power of Candy Johnson's magical hips, the active female body was frowned upon. The active female body in these early films was not accepted. It was fine for girls to be active so long as they were not too powerful. In Ride the Wild Surf (Taylor, 1964) a group of surfers visit Oahu Island off Hawaii and one of the surfers, Chase (Peter Brown), is wooed by tomboy, Augie Poole (Barbara Eden), whom he describes as a'girl nut'. Augie, a quasimale who wears trousers, throws Chase using a judo move. However, even with her foot on his neck, he refuses to take back his insult and, looking at the surfers, she realizes that she has overstepped the boundaries of male/female relationships. Barbara Eden, was also a third Dan Lack Belt in ju-jitsu, and Eden starred as Jennie, a genie in an early 1960s sitcom, I Dream of Jeannie (1965-70).

Here, it is worth reflecting upon the ways in which patriarchy attempted to return women to their domestic environment. In Bewitched and I Dream of Jeannie, a witch and a genie, wishing to fit into a suburban, domestic setting, voluntarily renounce their powers to become housewives and, in the case of Bewitched, mother. As Susan Douglas suggests 'a significant proportion of the pop culture moguls were trying to acknowledge the impending release of female sexual and political energy, while keeping it safely in a straitjacket' Douglas 1995: 126). In both shows the powerful female protagonists had to voluntarily deny their powers or confine them to their domestic environment, lest they cause anarchy in the male ordered world. Just as Jeannie and Samantha's powers were constrained by patriarchy, so were girl's bodies in surfsploitation films constrained. While the bikini may have shown the power of the female body to move objects and men, in reality, the bikini controlled

1. 2. 3. 4. 5. 6. 7. 8. 9. 10. 11. 12. 13. 14. 15. 16. 17. 18. 19. 20. 21. 22. 23. 24. 25. 26. 27. 28. 29. 30. 31. 32. 33. 34. 35. 36. 37. 38. 39. 40. 41. 42. 43. 44. 45. 46. 47. 48. 49. 50. 51. 52. 
1. the female body. While it connoted danger and eroticism, the strategies used to control the body, making it suitable to 'stuff' the bikini, into that 36/24/36inch size signalled the beginnings of the diet industry and an obsession with female body size.

The boom in surfsploitation films happened in a short three-year span: 1963-66. It was short-lived because it began just as America became enthralled by the wave of British beat groups that changed popular culture and music. In these films, the bikini connoted the allure of youth and surfing in binaries of sexuality/ innocence, modernity/primitivism, freedom/constriction and the passive yet active female body. Whilst the bikini was promoted to teenage girls through issues of sport, health and surf exploitation in the fashion industry, promotion and narratives of surfsploitation films emphasized the sexy and dangerous elements of the bikini and the active female body. Both sex and action were aligned through female agency, an agency that had to be tamed. In an era of developing civil rights and the growth of calls for female equality, the beach films contained and domesticated the power of the active female body through the restrictions and demands made upon them by the bikini. In surfsploitation films, the bikini articulated the dilemma of women at the beginning of the 1960s. There was a tacit acknowledgement that women were powerful, and yet they were expected to do the right thing, renounce their power in favour of a ring and domesticity.

\section{REFERENCES}

Alac, Patric (2002), The Bikini: A Cultural History, New York: Parkstone Press. Asher, William (1963), Beach Party, USA: American International Pictures.

— (1964a), Muscle Beach Party, USA: American International Pictures.

- (1964b), Bikini Beach, USA: American International Pictures.

— (1965a), Beach Blanket Bingo, USA: American International Pictures.

(1965b), How to Stuff a Wild Bikini, USA: American International Pictures.

Bava, Mario (1966), Dr. Goldfoot and the Girl Bombs, USA: American International Pictures.

Beach Boys (1965), 'California Girls', Recorded by Brian Wilson and Mike Love, Vinyl LP, Los Angeles, CA: Capitol.

Benedict, Richard (1965), Winter A-Go-Go, USA: Columbia Pictures.

Bennett, Compton and Marton, Andrew (1950), King Solomon's Mines, USA: Metro-Goldwyn-Mayer.

Bewitched (1964-70, USA: Screen Gems and Ashmount Productions).

Bronfen, Elizabeth (1998), The Knotted Subject: Hysteria and Its Discontents, Princeton, NJ: Princeton University Press.

Caine, Andrew (2001), 'The AIP beach movies: Cult films depicting subcultural activities', Scope Online Journal of Film Studies, December, http://www. nottingham.ac.uk/scope/documents/2001/december-2001/caine.pdf.

Canniford, Robin, and Karabbaba, Eminegül (2013), 'Partly Primitive: discursive constructions of the domestic surfer', in Consumption Markets and Culture. 16:2, pp. 119-144.

Canniford, Robin, and Shankar, Avi (2011), 'Marketing the savage: Appropriating tribal tropes', in B. Cova, R. V. Kozinets and A. Shankar (eds), Consumer Tribes, Abingdon, Oxon and New York: Routledge, pp. 35-48.

Corman, Roger and Jerome, Jim (1998), How I Made A Hundred Movies In Hollywood and Never Lost a Dime, New York: DaCapo Press. 
Craik, Jennifer (1993), The Face of Fashion: Cultural Studies in Fashion, London: Routledge.

Doherty, Thomas (1988), Teenagers and Teenpics: the Juvenilization of American Movies in the 1950s, London and Boston: Unwin Hyman.

Douglas, Susan J. (1995), Where the Girls Are: Growing Up Female with the Mass Media, New York: Three Rivers Press.

Driscoll, C. (2011), Teen Film: A Critical Introdution, London, Oxford, New York, New Delhi and Sydney: Berg Publishers.

Fiske, John (1983), 'Surfalism and sandiotics: The beach in Oz culture', Australian Journal of Cultural Studies, 1:2, pp. 120-47.

Friedan, B. (1963), The Feminine Mystique, New York: W W Norton.

Haskell, Molly (1974), From Reverence to Rape: The Treatment of Women in the Movies, New York: Rinehart and Winston.

I Dream of Jeannie (1965-70, USA: Screen Gems).

Kennedy, Sarah (2007), The Swimsuit: A Fashion History from 1920s Biarritz and the Birth of the Bikini to Sportswear Styles and Fahion Trends, London: Carlton Books.

Kinsey, Alfred C., Wardell Pomeroy, B., Martin, Clyde E. and Gebhard, Paul H. (1953), Sexual Behavior in the Human Female, Bloomington, IN: Indiana University Press.

Levin, H. (1960), Where the Boys Are, USA: Metro-Goldwyn-Mayer.

Lisanti, Thomas (2005), Hollywood Surf and Beach Movies: The First Wave, 19591969, Jefferson: McFarland and Co.

Martinson, Leslie H. (1964), For Those Who Think Young, USA: United Artists.

May, Elaine Tyler (1988), Homeward Bound: American Families in the Cold War Era, New York: Basic Books.

May, Kirse Granat (1999), Suburban Eden: Californian Youth Images in Popular Culture 1955-1966, unpublished Ph.D. thesis, Salt Lake City: University of Utah.

- (2002), Golden State, Golden Youth: The California Image in Popular Culture, 1955-1966, Chapel Hill: University of North Caroline Press.

McGee, Mark Thomas (1984), Fast and Furious: The Story of American International Pictures, Jefferson: McFarland and Co.

- (1996), Faster and Furiouser: Revised and Fattened Fable of American International Pictures, Jefferson: McFarland and Co.

Morris, Gary (1993), 'Beyond the beach: Social and formal aspects of AIP's beach party movies', Journal of Popular Film and Television, 21:1, pp. 1-11.

Ormrod, Joan (2003), 'Issues of gender in Muscle Beach Party (1964)', Scope Online Journal of Film Studies, http://www.nottingham.ac.uk/film/ journal/.

Radner, Hilary and Luckett, Moya (1999), 'Sensuous women and single girls: Reclaiming the female body on 1960s television', in Hilary Radner and Moya Luckett (eds), Swinging Single: Representing Sexuality in The Sixties, Minneapolis: University of Minnesota Press, pp. 277-98.

Rothaar, James (2006), 'Bikinis exposed: Happy 60th anniversary!', Bikini Picture History, https://web.archive.org/web/20101130155941/http://www. justluxe.com:80/resources/history-bikini.php. Accessed 9 April 2018.

Rozier, W. (1952), The Girl in the Bikini, France: Atlantis Films.

Rutsky, R. L. (2000), 'Surfing the other: Ideology on the beach', Film Quarterly, 52:4, pp. 12-23, https://search.proquest.com/openview/1ed5080472e1a1e 04c59679248b0119e/1?pq-origsite=gscholar\&cbl=40894. Accessed 9 April 2018.

1.

2.

3.

4.

5.

6.

7.

8.

9.

10.

11.

12.

13.

14.

15.

16.

17.

18.

19.

20.

21.

22.

23.

24.

25.

26.

27.

28.

29.

30.

31.

32.

33.

34.

35.

36.

37.

38.

39.

40.

41.

42.

43.

44.

45.

46.

47.

48.

49.

50.

51.

52. 
Schmidt, Christine (2012), The Swimsuit: Fashion from Poolside to Catwalk, London and New York: Berg.

The Shirelles (1960), 'Will You Still Love Me Tomorrow', Recorded by Gerry Goffin and Carole King, B side on Tonight's the Night, Vinyl LP, New York: Bell Sound Studios.

Steele, Valerie (1996), Fetish: Fashion, Sex and Power, Oxford and New York: Oxford University Press.

Taurog, Norman (1965), Dr. Goldfoot and the Bikini Machine, USA: American International Pictures.

Trubo, Richard and Arkoff, Samuel Z. (1992), Flying Through Hollywood by the Seat of my Pants: From the Man who Brought you I was a Teenage Werewolf and Muscle Beach Party, New York: Birch Lane Press.

Vadim, Roger (1957), And God Created Woman, USA: Éditions René Chateau Kingsley International Pictures.

Walker, Nadeane (1969), 'Quant fashions don't reveal everything', Reading Eagle, 21 October, p.10.

Weinrib, Lennie (1965), Beach Ball, USA: Paramount.

Weis, Don (1966), The Ghost in the Invisible Bikini, USA: American International Pictures.

Wendkos, Paul (1959), Gidget, USA: Columbia Pictures.

Whitney, William N. (1965), The Girls on the Beach, USA: Paramount Pictures.

Young, Terence (1962), Dr. No, United Kingdom: United Artists.

\section{SUGGESTED CITATION}

Ormrod, J. (2018), '1960s surfsploitation films: Sex, the bikini and the active female body', Film, Fashion \& Consumption, 7:2, pp. 147-63, doi: 10.1386/ ffc.7.2.147_1

\section{CONTRIBUTOR DETAILS}

Joan Ormrod is a senior lecturer at Manchester Metropolitan University and the editor of Routledge's Journal of Graphic Novels and Comics. Her research is interdisciplinary in crossing youth culture, comics, science fiction and fantasy. Her latest publications are in girl's romance comics, fan studies, promotional culture, Wonder Woman and time travel.

Contact: Department of Media, 307 Chatham Building, Manchester Metropolitan University,Cavendish St., Manchester, M15 6BR.

E-mail: j.ormrod@mmu.ac.uk

(D) https://orcid.org/0000-0002-3531-8938

Joan Ormrod has asserted her right under the Copyright, Designs and Patents Act, 1988, to be identified as the author of this work in the format that was submitted to Intellect Ltd. 